\title{
Factors Associated with Late Diagnosis of Oral Cancer
}

\author{
Jerlucia Cavalcanti das Neves ${ }^{1 *}$, Lívia Soraya Toledano², Fabiana Moura da Motta Silveira1, \\ Paulo Sávio Angeiras de Góes ${ }^{3,4}$ \\ ${ }^{1}$ Postgraduate Program in Dentistry (Collective Health), Faculdade de Odontologia de Pernambuco, \\ Universidade de Pernambuco, Recife, Brazil \\ ${ }^{2}$ Faculdade de Odontologia do Recife, Recife, Brazil \\ ${ }^{3}$ Epidemiology and Public Health, University of London, London, UK \\ ${ }^{4}$ Department of General and Preventive Dentistry, Universidade Federal de Pernambuco, Recife, Brazil \\ Email: Jerlucia@Hotmail.Com
}

Received 7 February 2015; accepted 21 February 2015; published 26 February 2015

Copyright (C) 2015 by authors and Scientific Research Publishing Inc.

This work is licensed under the Creative Commons Attribution International License (CC BY).

http://creativecommons.org/licenses/by/4.0/

(c) (i) Open Access

\section{Abstract}

Objective: The aim of the present study was to determine associations between the late diagnosis of oral cancer and demographic/clinical factors. A quantitative cross-sectional study was carried out in 2007. Material and Method: Oral tumors were recorded based on the TNM staging system, with $\mathrm{T} 1$ and $\mathrm{T} 2$ considered early diagnosis and $\mathrm{T} 3$ and $\mathrm{T} 4$ considered late diagnosis. Results: Patient age ranged from 30 to 105 years (mean: 64.7). Just over half of the patients $(54.9 \%)$ resided in urban areas and approximately $1 / 4(25.7 \%)$ had an agricultural occupation. The majority had smoking habits $(89.9 \%)$ and consumed alcohol $(62.5 \%)$. The most frequent tumor site was the tongue $(42.4 \%)$, followed by the hard palate $(19.2 \%)$ and lip $(12.2 \%)$. The majority $(70.1 \%)$ were in advanced stages (III and IV). A greater percentage of smokers were in advanced stages than non-smokers. The percentage of cases in the early stages was lowest when the tumor was located in the tongue (14.1\%) and highest when located in the buccal mucosa $(80.0 \%)$. Conclusion: The main causes of the late diagnosis of oral cancer are insufficient training on the part of physicians and dentists in the field of pathology, delays on the part of patients in seeking medical assistance and deficient access to quality medical care, reflecting the absence of preventive public health programs and an effective healthcare system.

\section{Keywords}

Oral Cancer, Late Diagnosis, Clinical Stage

\footnotetext{
${ }^{*}$ Corresponding author.
} 


\section{Introduction}

Approximately $10 \%$ of the malignant tumors that occur in the human body are located in the mouth. Oral cancer has the sixth highest incidence among the different forms of cancer worldwide. Excluding skin cancer, oral cancer is the most common form of cancer in the head and neck region (38\%), with predominance in the male gender, $75 \%$ of cases diagnosed in the seventh decade of life and $95 \%$ of cases classified as squamous cell carcinoma. Low survival rates underscore the need for greater care offered to patients with oral cancer in the Brazilian population [1].

Brazil is one of the countries with the highest incidence of oral cancer in the world. Data from the Brazilian National Cancer Institute demonstrate an estimated incidence of 14,120 cases of mouth cancer in 2010 (10,330 men and 3790 women). These data make oral cancer the fifth most frequent form of cancer among men and the sixth most frequent among women in the country. A total of 6214 deaths related to oral cancer were recorded in 2008 (4898 men and 1316 women) [2].

Oral squamous cell carcinoma is the most common form of cancer in the oral cavity. However, differences are found between countries as well as between regions within a single country regarding the incidence of this condition. This finding may stem from local differences in the prevalence of risk factors. Population-based studies addressing oral cancer and associated risk factors are scarce in Brazil [1].

It has been well established that the occurrence of oral cancer is directly associated with smoking habits and the consumption of alcoholic beverages [3]. Tobacco consumption is the major risk factor for the development of the disease. Individuals who smoke and consume alcoholic beverages have an increased risk of developing cancer of the mouth, pharynx and larynx. The consumption of the beverage mate, known in Brazil as chimarrão, is also considered a risk factor [4]. Despite discrepant results, the use of dentures and teeth in poor condition are not considered risk factors for oral cancer. In lip cancer, the most important factor is actinic radiation. The possible participation of viruses and oncogenes in oral carcinoma needs to be better established [5] [6].

The Brazilian National Cancer Care Policy (incorporated in Ordinance $n^{\circ} 2048$ from September $3^{\text {rd }}$, 2009) defines the broad-scoped control of cancer throughout the country and considers various components-from actions directed at prevention to high-complexity care-integrated in cancer care networks with the aim of reducing the incidence of cancer and associated mortality rates [2].

A number of researchers report that late diagnosis is the main problem related to oral cancer, generating higher morbidity/mortality rates. A growing number of patients arrive at healthcare services in advanced stages of the disease, with a subsequent reduced chance of effective, curative treatment [7]-[11]. According to Teixeira et al. [12], more than $50 \%$ of cases are diagnosed in advanced stages. Despite the fact that the mouth is easily accessed for the purposes of examination on the part of dentists, general physicians and even the patient himself/ herself (self-exam), allowing the early detection of suspected lesions, diagnosis in most cases is late [13] [14].

Early diagnosis is not necessarily easy, as both patients and healthcare professionals underestimate initial lesions, which are generally asymptomatic. This suggests that 1) physicians and dentists have gaps in their knowledge of pathology, 2) patients delay seeking medical assistance and 3) access to quality medical care is deficient, reflecting the absence of preventive public health programs and an effective healthcare system [11].

The aim of the present study was to determine associations between the late diagnosis of oral cancer and demographic/clinical factors in order to outline the profile of such patients.

\section{Material and Methods}

A quantitative, cross-sectional study was carried out throughout the year 2007 at the Cancer Hospital of Pernambuco, which is a reference hospital for the treatment of cancer in the state of Pernambuco (northeastern Brazil). The sample was made up of 172 cases of oral cancer, which corresponded to all patients treated for this type of cancer at the hospital in 2007. The data were collected based on a retrospective survey of medical charts in the Head and Neck Sector.

The socio-demographic variables investigated were gender, age, place of residence (urban or rural area) and lifestyle habits (smoking and alcohol consumption). The clinical data investigated were location of the tumor, type of treatment and clinical stage of the tumor. Tumors were recorded based on the TNM staging system, with $\mathrm{T} 1$ and $\mathrm{T} 2$ considered early diagnosis and T3 and T4 considered late diagnosis (advanced stages).

For the data analysis, absolute and percentage distributions were determined, statistical measures were obtained (mean, standard deviation and median values) and Pearson's correlation coefficients were calculated (de- 
scriptive statistical methods). Either Pearson's chi-square test or Fisher's exact test was employed, when appropriate, with the level of significance set to $5 \%(\mathrm{p}<0.05)$. The Statistical Package for the Social Sciences (SPSS version 15) was used for entering the data and performing the statistical calculations.

The present study involved a documental analysis of secondary data and received approval from the Human Research Ethics Committee of the Cancer Hospital of Pernambuco under process number 25/2009.

\section{Results}

A total of 172 patients were analyzed in the present study. Patient age ranged from 30 to 105 years (mean: 64.71; standard deviation: 14.81 years; median: 64.00 years; coefficient of variation: 22.89\%). The majority of patients were male (71.5\%). Just over half were from urban areas (54.9\%). Approximately 1/4 (25.7\%) had an agricultural occupation and the rest had other occupations (69.7\%); however, data on occupation were recorded only for 109 cases. The majority had smoking habits (89.9\%) and consumed alcohol (62.5\%); however, data on smoking and alcohol consumption were not recorded on 44 and 33 medical charts, respectively.

Information on the stage of the disease was recorded on 147 charts. The largest percentage (44.2\%) was classified as Stage IV, followed by Stage III (25.9\%) and Stage II (19.0\%). Thus, the majority was in the late stage (III and IV; 70.1\%). Biopsy was incisional in most cases (97.1\%). The most frequent tumor site was the tongue (42.4\%), followed by the hard palate (19.2\%) and lip (12.2\%). The majority of patients underwent treatment (82.0\%), the most frequent of which was radiotherapy (39.0\%), followed by a combination of more than one type of treatment (31.2\%) and surgery (21.3\%). Death occurred in $17.4 \%$ of the patients.

Table 1 displays the data on stage classification according to age, gender, occupation and place of residence. The percentage of the early stage was lowest among patients aged 50 to 69 years (20.6\%) and was similar in the other two age groups. This percentage was higher among female patients (37.5\% vs. 27.1\%); lower among those with an agricultural occupation (24.2\%) in comparison to those with other occupations (34.8\%); and lower among those residing in rural areas (26.6\%) than those residing in urban areas (32.9\%). However, no statistically significant associations were found between stage classification and any of these variables $(p>0.05)$.

Table 2 displays the data on stage classification according to smoking habits and alcohol consumption. The percentage of patients in the early stage was lower among those with smoking habits (26.1\%) than those without this habit (60.0\%) and was similar between those who consumed alcohol (26.8\%) and those who did not (33.3\%). Smoking habit was the only one of these two variables significantly associated with stage classification ( $<$ 0.05; OR: 4.24; OR interval that excludes 1.00).

Table 3 displays the data on stage classification according to type of biopsy, location of tumor, history of treatment, type of treatment and death. Stage classification was significantly associated with tumor site and type of treatment. The percentage of cases in the early stage was lowest when the tumor site was the tongue (14.1\%) and highest when the site was the buccal mucosa (80.0\%). Moreover, this percentage was lowest when the patient was submitted to radiotherapy/chemotherapy (19.6\%) and highest when the treatment was surgery (64.3\%).

\section{Discussion}

Most studies on the clinical-epidemiological characteristics of squamous cell carcinoma of the oral cavity offer similar prevalence data for men and individuals with smoking and drinking habits, with a mean age between the $5^{\text {th }}$ and $6^{\text {th }}$ decades of life [10] [12] [15]. The profile of the present sample is similar to that described in the literature, as the patients were predominantly male (71.5\%), aged 30 to 105 years (median: 64 years) and the majority had smoking habits (89.9\%) and consumed alcoholic beverages (62.5\%).

Oral cancer was diagnosed in the earlier stages more among women. This may be explained by differences reported in the literature between men and women with regard to health care [16]-[20]. According to the authors cited, women are generally more attentive to signs and symptoms of illness, which, together with a greater concern for bodily care, makes this group seek care earlier in comparison to men.

Soudry et al. [21] carried out a study to evaluate the possible effect of age on clinical behavior and survival in cases of squamous cell carcinoma of the tongue. The authors report that the tumor was in advanced stages among patients under 30 years of age and the pattern of the disease was different from that seen in the older age group, which may be attributed to biological behavior related to age or the delayed diagnosis of cancer. In the present study, patients between 50 and 69 years of age had the highest percentage of late diagnosis of oral cancer (79.4\%), whereas this figure was $65.2 \%$ among patients under 49 years of age and $62.1 \%$ among those aged 
Table 1. Stage classification according to age, gender, occupation and place of residence.

\begin{tabular}{|c|c|c|c|c|c|c|c|c|}
\hline \multirow{3}{*}{ Variable } & \multicolumn{4}{|c|}{ Stage } & & & \multirow{3}{*}{ p-value } & \multirow{3}{*}{ OR (95\% CI) } \\
\hline & \multicolumn{2}{|c|}{ Early } & \multicolumn{2}{|c|}{ Late } & \multicolumn{2}{|c|}{ TOTAL } & & \\
\hline & $\mathrm{n}$ & $\%$ & $\mathrm{n}$ & $\%$ & $\mathrm{n}$ & $\%$ & & \\
\hline \multicolumn{9}{|c|}{ - Age (years) } \\
\hline Up 49 & 8 & 34.8 & 15 & 65.2 & 23 & 100.0 & $\mathrm{p}^{(1)}=0.099$ & 1.00 \\
\hline 50 to 69 & 13 & 20.6 & 50 & 79.4 & 63 & 100.0 & & $0.49(0.17$ to 1.40$)$ \\
\hline 70 or older & 22 & 37.9 & 36 & 62.1 & 58 & 100.0 & & 1.15 (0.42 to 3.14$)$ \\
\hline TOTAL & 43 & 29.9 & 101 & 70.1 & 144 & 100.0 & & \\
\hline \multicolumn{9}{|l|}{ - Gender } \\
\hline Male & 29 & 27.1 & 78 & 72.9 & 107 & 100.0 & $\mathrm{p}^{(1)}=0.221$ & 1.00 \\
\hline Female & 15 & 37.5 & 25 & 62.5 & 40 & 100.0 & & 1.61 (0.75 to 3.48$)$ \\
\hline TOTAL & 44 & 29.9 & 103 & 70.1 & 147 & 100.0 & & \\
\hline \multicolumn{9}{|l|}{ - Occupation } \\
\hline Agriculture & 6 & 24.0 & 19 & 76.0 & 25 & 100.0 & $\mathrm{p}^{(1)}=0.322$ & 1.00 \\
\hline Other & 23 & 34.8 & 43 & 65.2 & 66 & 100.0 & & 1.69 (0.59 to 4.83$)$ \\
\hline TOTAL & 29 & 31.9 & 62 & 68.1 & 91 & 100.0 & & \\
\hline \multicolumn{9}{|c|}{ - Place of residence } \\
\hline Rural & 17 & 26.6 & 47 & 73.4 & 64 & 100.0 & $\mathrm{p}^{(1)}=0.410$ & 1.00 \\
\hline Urban & 26 & 32.9 & 53 & 67.1 & 79 & 100.0 & & 1.36 (0.66 to 2.80$)$ \\
\hline TOTAL & 43 & 30.1 & 100 & 69.9 & 143 & 100.0 & & \\
\hline
\end{tabular}

${ }^{(1)}$ Pearson's chi-square test.

Table 2. Stage classification according to smoking habits and alcohol consumption.

\begin{tabular}{|c|c|c|c|c|c|c|c|c|}
\hline \multirow{3}{*}{ Variable } & \multicolumn{4}{|c|}{ Stage } & & & \multirow{3}{*}{ p-value } & \multirow{3}{*}{ OR (95\% CI) } \\
\hline & \multicolumn{2}{|c|}{ Early } & \multicolumn{2}{|c|}{ Late } & \multicolumn{2}{|c|}{ TOTAL } & & \\
\hline & $\mathrm{n}$ & $\%$ & $\mathrm{n}$ & $\%$ & $\mathrm{n}$ & $\%$ & & \\
\hline \multicolumn{9}{|l|}{ - Smoking } \\
\hline Yes & 29 & 26.1 & 82 & 73.9 & 111 & 100.0 & $\mathrm{p}^{(1)}=0.033^{*}$ & 1.00 \\
\hline No & 6 & 60.0 & 4 & 40.0 & 10 & 100.0 & & 4.24 (1.12 to 16.10$)$ \\
\hline TOTAL & 35 & 28.9 & 86 & 71.1 & 121 & 100.0 & & \\
\hline \multicolumn{9}{|c|}{ - Alcohol consumption } \\
\hline Yes & 19 & 26.8 & 52 & 73.2 & 71 & 100.0 & $\mathrm{p}^{(2)}=0.458$ & 1.00 \\
\hline No & 14 & 33.3 & 28 & 66.7 & 42 & 100.0 & & 1.37 (0.60 to 3.14$)$ \\
\hline TOTAL & 33 & 29.2 & 80 & 70.8 & 113 & 100.0 & & \\
\hline
\end{tabular}

*Significant difference to 5.0\%; ${ }^{(1)}$ Fisher's exact test; ${ }^{(2)}$ Pearson's chi-square test.

70 years or older. The data in the present study were not conclusive with regard to the biological behavior of oral cancer in relation to age. However, the high percentages of late diagnosis in all three age groups clearly demonstrates a worrisome delay in initiating treatment among these patients, which may be due to the late discovery of the tumor or delayed access to cancer treatment centers, which, above all, contributes to the high morbidity-mortality rates associated with this disease. 
Table 3. Stage classification according to type of biopsy, location of tumor, history of treatment, type of treatment and death.

\begin{tabular}{|c|c|c|c|c|c|c|c|c|}
\hline \multirow{3}{*}{ Variable } & \multicolumn{4}{|c|}{ Stage } & & & \multirow{3}{*}{ p-value } & \multirow{3}{*}{ OR (95\% CI) } \\
\hline & \multicolumn{2}{|c|}{ Early } & \multicolumn{2}{|c|}{ Late } & \multicolumn{2}{|c|}{ TOTAL } & & \\
\hline & $\mathrm{n}$ & $\%$ & $\mathrm{n}$ & $\%$ & $\mathrm{n}$ & $\%$ & & \\
\hline \multicolumn{9}{|l|}{ - Type of biopsy } \\
\hline Incisional & 43 & 30.5 & 98 & 69.5 & 141 & 100.0 & $\mathrm{p}^{(1)}=1.000$ & $* *$ \\
\hline Other (Excisional/Puncture) & 1 & 20.0 & 4 & 80.0 & 5 & 100.0 & & \\
\hline TOTAL & 44 & 30.1 & 102 & 69.9 & 146 & 100.0 & & \\
\hline \multicolumn{9}{|l|}{ - Location } \\
\hline Tongue & 9 & 14.1 & 55 & 85.9 & 64 & 100.0 & $\mathrm{p}^{(1)}=0.001^{*}$ & ** \\
\hline Lip & 9 & 50.0 & 9 & 50.0 & 18 & 100.0 & & ** \\
\hline Gingiva/Alveolar ridge & 4 & 28.6 & 10 & 71.4 & 14 & 100.0 & & $* *$ \\
\hline Floor of mouth & 6 & 33.3 & 12 & 66.7 & 18 & 100.0 & & $* *$ \\
\hline Hard palate & 12 & 42.9 & 16 & 57.1 & 28 & 100.0 & & ** \\
\hline Buccal musosa & 4 & 80.0 & 1 & 20.0 & 5 & 100.0 & & ** \\
\hline TOTAL & 44 & 29.9 & 103 & 70.1 & 147 & 100.0 & & \\
\hline \multicolumn{9}{|l|}{ - Treatment } \\
\hline Yes & 38 & 32.2 & 80 & 67.8 & 118 & 100.0 & $\mathrm{p}^{(2)}=0.264$ & 1.74 (0.65 to 4.65$)$ \\
\hline No & 6 & 21.4 & 22 & 78.6 & 28 & 100.0 & & 1.00 \\
\hline TOTAL & 44 & 30.1 & 102 & 69.9 & 146 & 100.0 & & \\
\hline \multicolumn{9}{|l|}{ - Type of treatment } \\
\hline Radiotherapy/Chemotherapy & 9 & 19.6 & 37 & 80.4 & 46 & 100.0 & $\mathrm{p}^{(2)}=0.001^{*}$ & ** \\
\hline Surgery & 18 & 64.3 & 10 & 35.7 & 28 & 100.0 & & ** \\
\hline Combination of more than one type & 9 & 25.0 & 27 & 75.0 & 36 & 100.0 & & ** \\
\hline Palliative & 2 & 25.0 & 6 & 75.0 & 8 & 100.0 & & ** \\
\hline TOTAL & 38 & 32.2 & 80 & 67.8 & 118 & 100.0 & & \\
\hline \multicolumn{9}{|l|}{ - Death } \\
\hline Yes & 5 & 20.0 & 20 & 80.0 & 25 & 100.0 & $\mathrm{p}^{(2)}=0.234$ & 1.00 \\
\hline No & 39 & 32.0 & 83 & 68.0 & 122 & 100.0 & & 1.88 (0.66 to 5.38$)$ \\
\hline TOTAL & 44 & 29.9 & 103 & 70.1 & 147 & 100.0 & & \\
\hline
\end{tabular}

"Significant difference to $5.0 \% ;{ }^{* *}$ Not possible to determine due to very low frequencies; ${ }^{(1)}$ Fisher's exact test; ${ }^{(2)}$ Pearson's chi-square test.

Dedivits et al. [15] report that a large proportion of tumors of the tongue (the most frequent site in the sample) and the oropharynx were in Stages III and IV (53\% and 96\% of cases, respectively). However, no statistically significant associations were found between stage classification and smoking habits, drinking habits or denture use. Kao et al. [22], Chen et al. [23] and Lo et al. [9] also report that 50\% of cases of mouth cancer are discovered late (Stages III and IV). Likewise, the majority of tumors in the present study were in Stages III and IV (70.1\%). However, a significant association was found between smoking and stage of the tumor, as the majority of patients with smoking habits (73.9\%) had a late diagnosis (Stages III and IV). There was also a statistically significant association between stage classification and tumor site, as tumors located on the tongue had the lowest percentage of early diagnosis, whereas those located on the buccal mucosa were diagnosed earlier.

The absence of an oral cancer care system in the majority of states in Brazil needs to be addressed immediately. According to Borges et al. [10], the lack of such a system in the state of Mato Grosso theoretically con- 
tributes to the fact that patients with previously undiagnosed oral cancer present to the Mato Grosso Cancer Hospital in clinically advances stages of the disease. Leite and Koifman [24] analyzed the survival rate of patients with oral cancer at the Brazilian National Cancer Institute in Rio de Janeiro and found a correlation between clinical stage and mortality, as the mortality rate among patients in Stage I was $18.1 \%$, with this figure rising to $65.4 \%$ among those in Stage 4 . In the present study, $80 \%$ of the patients who died had late diagnoses (Stages III and IV). Such findings speak to the need for reflection regarding clinical approaches, access to diagnoses and access to hospital care as well as technical-scientific knowledge on the part of healthcare professionals responsible for making the diagnosis of oral cancer.

A growing number of cases of cancer have been identified in the state of Alagoas in a context of late diagnosis and little access to treatment. One hundred ten new cases of mouth cancer were diagnosed in 2008, with an increase in the number of patients with incurable cancer. Such patients are generally sent home, where they suffer pain and other symptoms of the disease until their death [11]. Thus, the early detection of mouth cancer by the basic healthcare network should be seriously considered. According to Borges et al. [10], universal access to diagnostic means will enable early intervention in cases of oral cancer.

The high percentages of cases of oral cancer diagnosed in late stages are a worldwide concern [25]-[29]. This situation leads to a higher mortality rate associated to this type of cancer in all countries, along with an increase in health-related expenditures, physical and psychological effects on patients submitted to mutilating treatment, operational difficulties with regard to the social rehabilitation of such patients, increased hospital stays and an increase in the demand for the different healthcare professionals involved in the multidisciplinary treatment required for these patients.

As the mouth is a site of easy access for both healthcare professionals and patients, lower percentage rates of the late diagnosis of oral cancer would be expected. This, however, is not the case. It is likely that a number of errors occur in the manner in which oral cancer is addressed in Brazil, especially with regard to the prevention and diagnosis of this disease. Conjecturing on the harsh reality of late diagnosis and its causes is not an easy task. Santos, Batista and Cangussu [11] suggest that physicians and dentists have gaps in their knowledge regarding the field of pathology, that patients delay in seeking medical assistance and that access to quality medical care is deficient, reflecting the absence of preventive public health programs and an effective healthcare system.

\section{Conclusion}

Greater attention to oral cancer should be given in the public healthcare system in Brazil, especially in the realm of primary care and prevention and the adequate training of healthcare professionals for the early diagnosis of potentially malignant tumors of the oral cavity. The public healthcare network should be capable of promptly treating such patients, thereby reducing the number of cases of advanced stages of the disease and allowing greater survival with an improved quality of life.

\section{References}

[1] Oliveira, L.R., Ribeiro-Silva, A. and Zucoloto, S. (2006) Perfil da incidência e da sobrevida de pacientes com carcinoma epidermóide oral em uma população brasileira. The Jornal Brasileiro de Patologia e Medicina Laboratorial, 42, 385-392. http://dx.doi.org/10.1590/S1676-24442006000500010

[2] Brasil, Ministério da Saúde. Instituto Nacional do Câncer (2010) Prevenção e detecção—Câncer de boca. http://www.inca.gov.br/conteudo view.asp?id=324

[3] Boyle, P., Macfarlane, G.J. and Scully, C. (1993) Oral Cancer-Necessity for Prevention Strategies. The Lancet, 342, 1129. http://dx.doi.org/10.1016/0140-6736(93)92119-E

[4] Franco, E.L., et al. (1989) Risc Factors for Oral Cancer in Brazil: A Case Control Study. International Journal of Cancer, 43, 992-1000. http://dx.doi.org/10.1002/ijc.2910430607

[5] Almeida, O.P. and Lopes, M.A. (2003) Prevenção das Doenças Bucais. In: Kriger, L., Ed., Promoção de Saúde Bucal: Paradigma, Ciência, Humanização, 3rd Edition, Artes Médicas, São Paulo, 463-473.

[6] Lissowska, J., et al. (2003) Smoking, Alcohol, Diet, Dentition and Sexual Practices in the Epidemiology of Oral Cancer in Poland. European Journal of Cancer Prevention, 12, 25-33. http://dx.doi.org/10.1097/00008469-200302000-00005

[7] Chen, Y.K., et al. (1999) Primary Oral Squamous Cell Carcinoma: An Analysis of 703 Cases in Southern Taiwan. Oral Oncology, 35, 173-179. http://dx.doi.org/10.1016/S1368-8375(98)00101-8 
[8] Jitomirski, F. (2000) Câncer Bucal. In: Pinto, V.G., Ed., Saúde Bucal Coletiva, 4th Edition, Santos, São Paulo, 445456.

[9] Lo, W.L., et al. (2003) Outcomes of Oral Squamous Cell Carcinoma in Taiwan after Surgical Therapy: Factors Affecting Survival. The Journal of Oral and Maxillofacial Surgery, 61, 751-758. http://dx.doi.org/10.1016/S0278-2391(03)00149-6

[10] Borges, D.M.L., et al. (2009) Mortalidade por cancer de boca e condição sócio econômica no Brasil. Cadernos de Saúde Pública, 25, 321-327. http://dx.doi.org/10.1590/S0102-311X2009000200010

[11] Santos, L.C.O., Batista, O.M. and Cangussu, M.C.T. (2010) Characterization of Oral Cancer Diagnostic Delay in the State of Alagoas. Brazilian Journal of Otorhinolaryngology, 76, 416-422.

[12] Teixeira, A.K.M., de Almeida, M.E.L., Holanda, M.E., Sousa, F.B. and de Almeida, P.C. (2009) Carcinoma espinocelular da cavidade bucal: Um estudo epidemiológico na Santa Casa de Misericórdia de Fortaleza. Revista Brasileira de Cancerologia, 55, 229-236.

[13] de Lima, A.A.S., França, B.H.S., Ignácio, S.A. and Baioni, C.S. (2005) Conhecimento de alunos universitários sobre câncer bucal. Revista Brasileira de Cancerologia, 51, 283-288.

[14] Kowalski, L.P., Franco, E.L., Torloni, H., Fava, A.S., de Andrade Sobrinho, J., Ramos, G., et al. (1994) Lateness of Diagnosis of Oral and Oropharyngeal Carcinoma: Factors Related to the Tumour, the Patient and Health Professionals. European Journal of Cancer Part B: Oral Oncology, 30, 167-173. http://dx.doi.org/10.1016/0964-1955(94)90086-8

[15] Dedivitis, R.A., França, C.M., Mafra, A.C.B., Guimarães, F.T. and Guimarães, A.V. (2004) Características clínicoepidemiológicas no carcinoma espinocelular de boca e orofaringe. Revista Brasileira de Otorrinolaringologia, 70, 3540. http://dx.doi.org/10.1590/S0034-72992004000100006

[16] Courtenay, W.H. (2000) Constructions of Masculinity and Their Influence on Men’s Well-Being: A Theory of Gender and Health. Social Science Medicine, 50, 1385-1401. http://dx.doi.org/10.1016/S0277-9536(99)00390-1

[17] Laurenti, R., Mello-Jorge, M.H.P. and Gotlieb, S.L.D. (2005) Perfil epidemiológico da morbi-mortalidade masculina. Ciência \& Saúde Coletiva, 10, 35-46. http://dx.doi.org/10.1590/S1413-81232005000100010

[18] Luck, M., Bamford, M. and Williamson, P. (2000) Men’s Health: Perspectives, Diversity and Paradox. Blackwell Sciences, London.

[19] Figueiredo, W. (2005) Assistência à saúde dos homens: Um desafio para os serviços de atenção primária. Ciência \& Saúde Coletiva, 10, 105-109. http://dx.doi.org/10.1590/S1413-81232005000100017

[20] Pinheiro, R.S., Viacava, F., Travassos, C. and dos Santos Brito, A. (2002) Gênero, morbidade, acesso e utilização de serviços de saúde no Brasil. Ciência \& Saúde Coletiva, 7, 687-707. http://dx.doi.org/10.1590/S1413-81232002000400007

[21] Soudry, E., Preis, M., Hod, R., Hamzany, Y., Hadar, T., Bahar, G., et al. (2010) Squamous Cell Carcinoma of the Oral Tongue in Patients Younger than 30 Years: Clinicopathologic Features and Outcome. Clinical Otolaryngology, 35, 307-312. http://dx.doi.org/10.1111/j.1749-4486.2010.02164.X

[22] Kao, S.-Y., Chen, Y.-W., Chang, K.-W. and Liu, T.-Y. (2009) Detection and Screening of Oral Cancer and Pre-Cancerous Lesions. Journal of the Chinese Medical Association, 72, 227-233. http://dx.doi.org/10.1016/S1726-4901(09)70062-0

[23] Chen, H.T. (1990) Theory-Driven Evaluations. Sage Publications, Newbury Park.

[24] Leite, I.C.G. and Koifman, S. (1998) Survival Analysis in a Sample of Oral Cancer Patients at a Reference Hospital in Rio de Janeiro, Brazil. Oral Oncology, 34, 347-352. http://dx.doi.org/10.1016/S1368-8375(98)00019-0

[25] Sciubba, J.J. (2001) Oral Cancer: The Importance of Early Diagnosis and Treatment. American Journal of Clinical Dermatology, 2, 239-251. http://dx.doi.org/10.2165/00128071-200102040-00005

[26] Brocklehurst, P., Kujan, O., Glenny, A.M., Oliver, R., Sloan, P., Ogden, G. and Shepherd, S. (2010) Screening Programmes for the Early Detection and Prevention of Oral Cancer. Cochrane Database of Systematic Reviews, Article ID: CD004150.

[27] Brocklehurst, P.R., Baker, S.R. and Speight, P.M. (2010) Oral Cancer Screening: What Have We Learnt and What Is There Still to Achieve? Future Oncology, 6, 299-304. http://dx.doi.org/10.2217/fon.09.163

[28] Steele, T.O. and Meyers, A. (2011) Early Detection of Premalignant Lesions and Oral Cancer. Otolaryngologic Clinics of North America, 44, 221-229. http://dx.doi.org/10.1016/j.otc.2010.10.002

[29] Warnakulasuriya, S., Kashyap, R. and Dasanayake, A.P. (2010) Is Workplace Screening for Potentially Malignant Oral Disorders Feasible in India? Journal of Oral Pathology Medicine, 39, 672-676. http://dx.doi.org/10.1111/j.1600-0714.2010.00915.x 
Scientific Research Publishing (SCIRP) is one of the largest Open Access journal publishers. It is currently publishing more than 200 open access, online, peer-reviewed journals covering a wide range of academic disciplines. SCIRP serves the worldwide academic communities and contributes to the progress and application of science with its publication.

Other selected journals from SCIRP are listed as below. Submit your manuscript to us via either submit@scirp.org or Online Submission Portal.
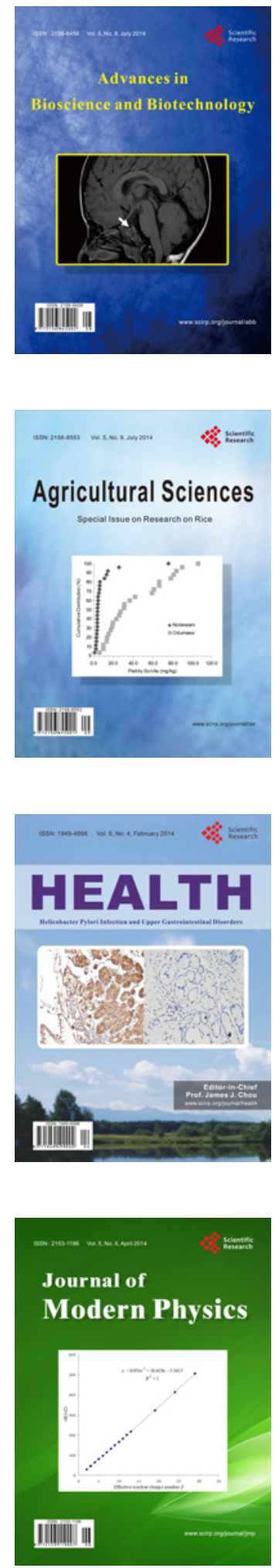
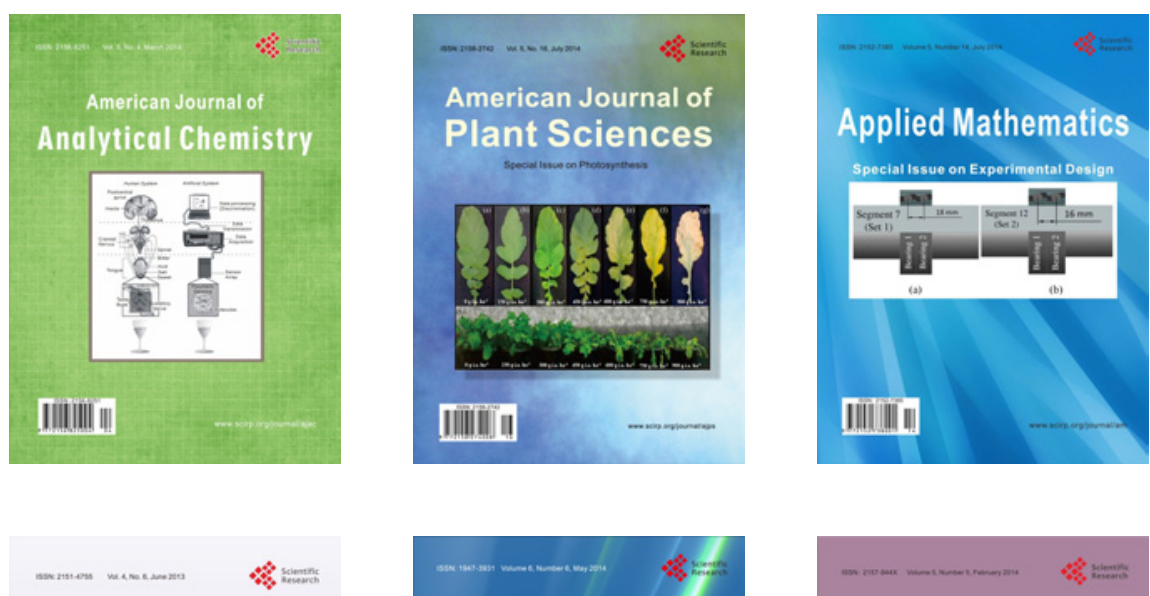

Creative Education
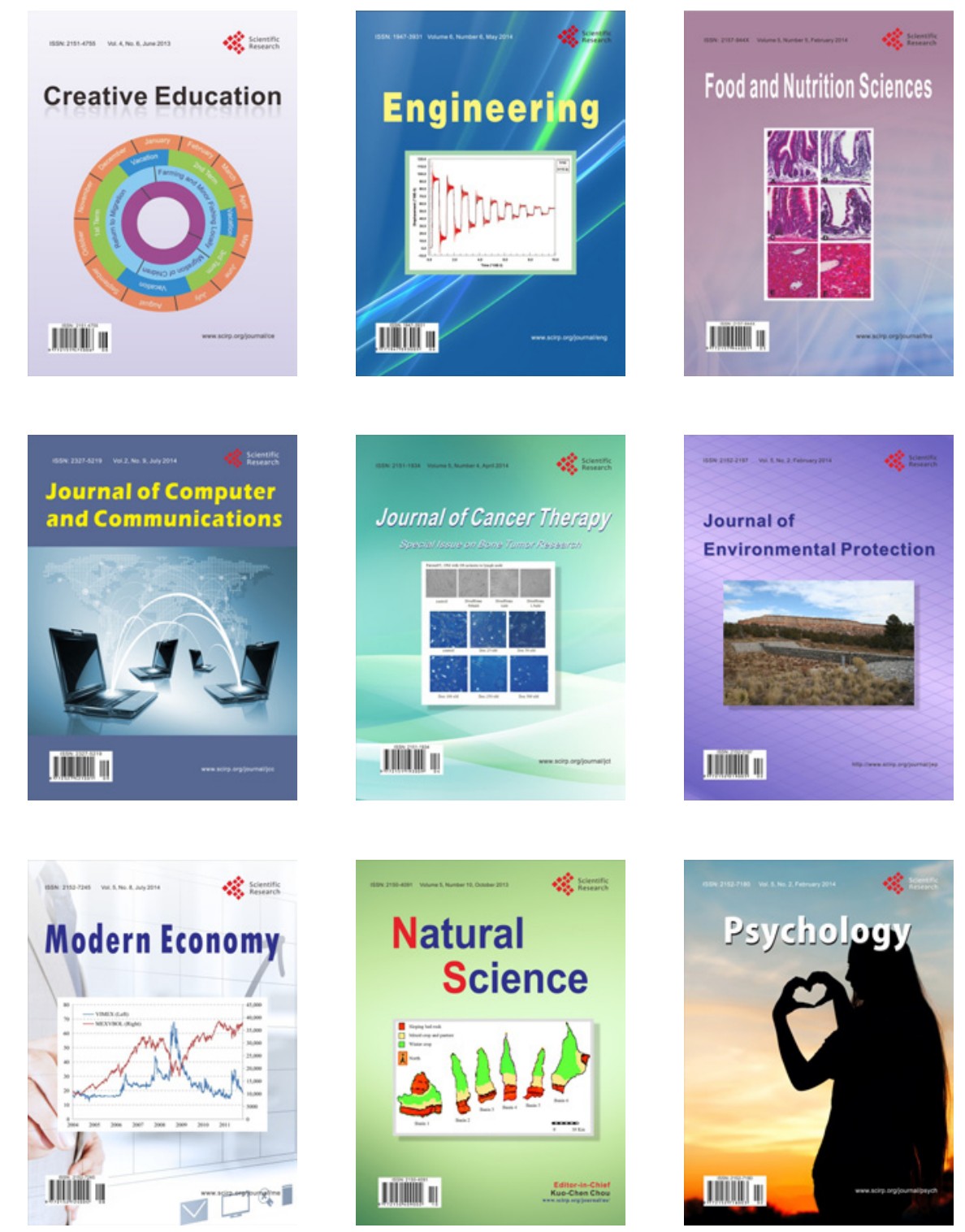